\title{
Experimental Study of a Cu-Mo Alloy Vapor Chamber
}

\author{
Daniel H.S. Obata ${ }^{1}$, Jeferson C. Fukushima ${ }^{1}$, Thiago Antonini Alves ${ }^{2, a}$, Márcio A. Bazani ${ }^{1}$ and Amarildo T. Paschoalini ${ }^{1}$ \\ ${ }^{1}$ São Paulo State University, 15.385-000, Ilha Solteira, SP, Brazil \\ ${ }^{2}$ Federal University of Technology - Paraná, 84.016-210, Ponta Grossa, PR, Brazil
}

\begin{abstract}
In this research, the thermal behavior of a vapor chamber embedded in the base of a heat sink was experimentally analyzed considering the influence of the heat source position. The vapor chamber was produced by a copper and molybdenum alloy with length of $240 \mathrm{~mm}$, width of $54 \mathrm{~mm}$, thickness of $3 \mathrm{~mm}$, and capillary structures composed by copper screen meshes. The working fluid used was de-ionized water. The pure aluminum heat sink was cooled by air forced convection and the evaporator vapor chamber was heated using an electrical resistor simulating integrated circuit power dissipation. The experimental tests were done in a suction type wind tunnel with open return for a heat load varying from 20 to $80 \mathrm{~W}$, for an airflow velocity varying from 1 to $4 \mathrm{~m} / \mathrm{s}$, and for three different heat source positions. The experimental results showed that, independently of the heat source position, the considered vapor chamber worked successfully, maintaining low operating temperature.
\end{abstract}

\section{Introduction}

The vapor chambers, also known as flat heat pipes, are heat exchangers with phase change, which can be a good alternative to the application in thermal management of microelectronics. Vapor chambers are more efficient than cylindrical heat pipes due to their capability on transferring heat in two directions [1].

Vapor chambers can be embedded in the base of a heat sink to enhance the heat spreading at the base of the heat sink. The vapor chamber spreads heat effectively across the sink base before it gets distributed to the fins. The result is more effective than convective cooling as the fins base temperature will be higher, providing better use of the fins at the outer edge of the heat sink [2].

Major advantages of vapor chamber include a very high thermal conductance, no pumping power requirements, no moving parts, and relatively low pressure drops. More details on the principle of the vapor chambers and heat pipes can be found in [3].

Koito et al. [4] and Chen et al. [5] analyzed the thermal performance of a vapor chamber/heat sink set. In their researches, the vapor chamber was produced by copper with sintered copper powder capillary structure, the working fluid was water, and the heat sink was produced by aluminum.

However, in the present research, the vapor chamber was produced by $\mathrm{Cu}-\mathrm{Mo}$ alloy with capillary structures made of copper screen meshes, the working fluid was deionized water, and the heat sink was produced by pure aluminum.

\section{Description of the Vapor Chamber}

The commercial vapor chamber used in this research, shown in Figure 1, was produced by a $\mathrm{Cu}-\mathrm{Mo}$ alloy with length of $240 \mathrm{~mm}$, width of $54 \mathrm{~mm}$, thickness of $3 \mathrm{~mm}$, and capillary structure composed by copper screen meshes. The working fluid used was de-ionized water.

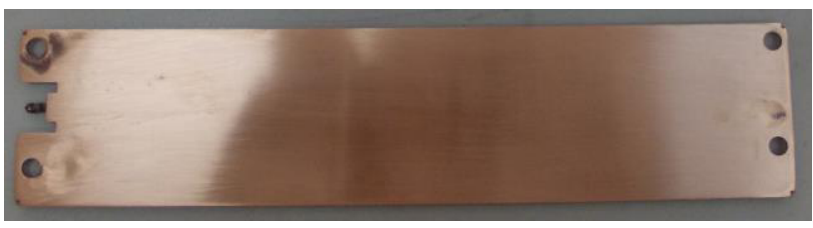

Figure 1. $\mathrm{Cu}-\mathrm{Mo}$ alloy vapor chamber.

Figure 2 shows the capillary structures of the evaporation and condensation regions of the vapor chamber.

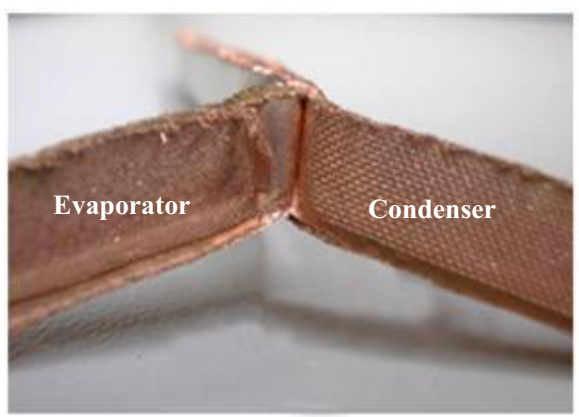

Figure 2. Capillary structure.

\footnotetext{
a Corresponding author: thiagoaalves@utfpr.edu.br
} 
An overlap of two layers of copper screen meshes was observed in the evaporation region where there is evaporation of the working fluid. On the other hand, there is only one copper screen mesh in the condensation region, where the vapor will change to liquid phase and there will be recirculation of the working fluid by capillarity effect [6].

Figures 3(a) and 3(b) show micro-scale images of evaporator and condenser structures, respectively. The images were obtained by Backscattered Electron Detector (BSD) for Scanning Electron Microscope (SEM). Figure 3(a) shows an overlap of a Mesh \#200 over a Mesh \#100 in evaporator. On the other hand, in the condenser, Figure 3 (b), there is only one $\mathrm{Cu}$ Mesh \#100.

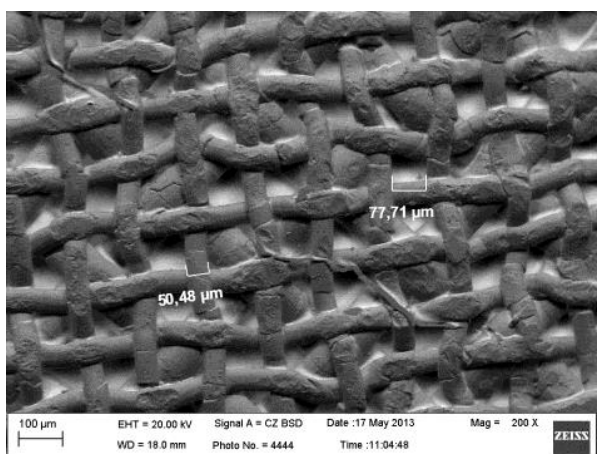

(a) evaporation region

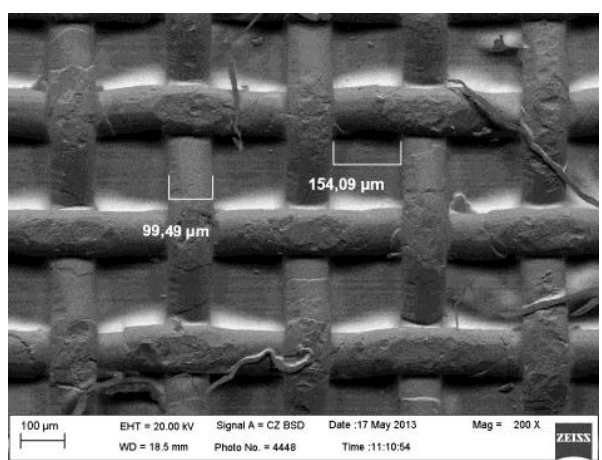

(b) condensation region

Figure 3. Micro-scale view of the wick structure of the vapor chamber.

\section{Experimental Procedure}

The experimental tests were performed in a suction type wind tunnel with open return, as shown in Figure 4(a). The tests section had length of $500 \mathrm{~mm}$, width of $360 \mathrm{~mm}$, and height of $60 \mathrm{~mm}$. An aluminum heat sink with eight fins of height of $20 \mathrm{~mm}$, thickness of $1 \mathrm{~mm}$, and pitch of $0.6 \mathrm{~mm}$, with a base of length of $240 \mathrm{~mm}$, width of 55 $\mathrm{mm}$, and thickness of $4.7 \mathrm{~mm}$ was embedded on top of the vapor chamber. The vapor chamber/heat sink set was mounted on the tests section lower wall - Figure 4(b). The vapor chamber was heated by a power supply (Minipa $^{\mathrm{TM}}$ MPL-3303) applying a potential difference in an electrical resistor, simulating power dissipation of a heat source. The vapor chamber temperatures were measured using K-type thermocouples (Omega ${ }^{\mathrm{TM}}$ ) and a data acquisition system (Hottinger Baldwin Messtechnik MGC Plus AB22A with 32 channels data logger and a Dell ${ }^{\mathrm{TM}}$ microcomputer).

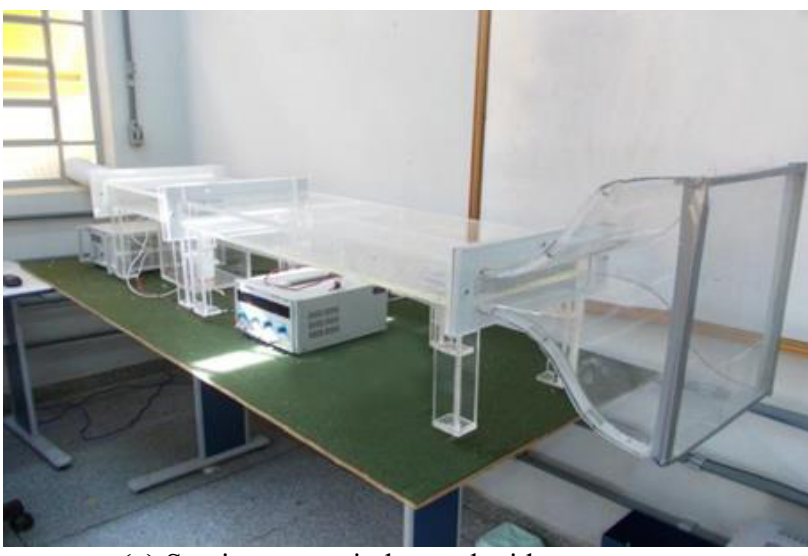

(a) Suction type wind tunnel with open return

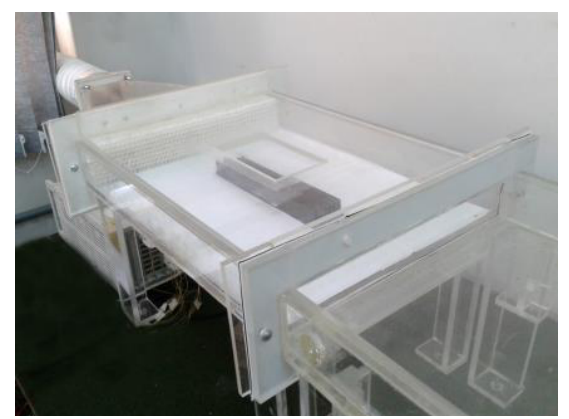

(b) tests section

Figure 4. Test rig.

\section{Experimental Results}

The experimental results regarding thermal behavior of the copper and molybdenum alloy vapor chamber/pure aluminum heat sink set are presented. Tests were performed to a heat load varying from 20 to $80 \mathrm{~W}$, to an airflow velocity varying from 1 to $4 \mathrm{~m} / \mathrm{s}$, and to three different heat source positions: $30 \mathrm{~mm}, 120 \mathrm{~mm}$, and $210 \mathrm{~mm}$ (Figure 5), comprising 48 experimental settings.

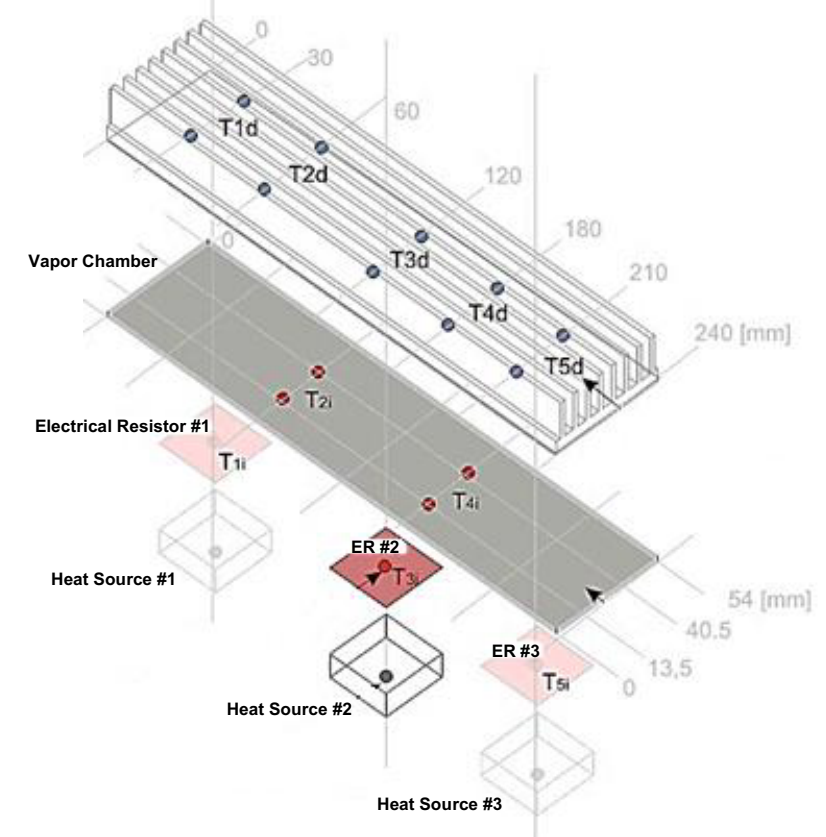

Figure 5. Different heat source positions. 
For each setting three tests were performed. The measurements uncertainties were estimated for temperature, heat load, and airflow velocity. Considering the accuracy of the temperature sensors (K-type thermocouples) and the data logger uncertainties, the measured temperature uncertainty was of $\pm 0.5^{\circ} \mathrm{C}$. The electrical power input uncertainty was of $\pm 3.1 \mathrm{~W}$, considering the power supply unit and the data logger uncertainties. Finally, the airflow velocity uncertainty was of $\pm 0.05 \mathrm{~m} / \mathrm{s}$, considering the uncertainties of the Pitot Tube and the inclined tube manometer.

The behavior of the vapor chamber average temperature with the heat load parameterized in the airflow velocity for each heat source position analyzed is shown in Figure 6 and Table 1. As expected, independently of the airflow velocity and the heat source position, the vapor chamber average temperature increases with the increasing of heat load. Furthermore, independently of the heat load and the heat source position, the operating temperature of the vapor chamber decreases with the increasing of airflow velocity. Finally, considering the influence of the heat source position, it is observed that the vapor chamber average temperature of Heat Sources \#2 and \#3 are similar, while the temperature of Heat Source \#1 is higher. This is due to the existence of the vapor chamber load terminal in the Heat Source \#1 region. It can be noticed that the measured minimum and maximum temperatures of the vapor chamber were $63.8{ }^{\circ} \mathrm{C}$ and $297.8{ }^{\circ} \mathrm{C}$, respectively, while the ambient temperature was kept at $24.0^{\circ} \mathrm{C}$.

Table 1. Experimental results: vapor chamber average temperatures $\left[{ }^{\circ} \mathrm{C}\right]$

(a) Heat Source \#1

\begin{tabular}{|c|c|c|c|c|}
\hline \multirow{2}{*}{$\begin{array}{l}\text { Heat } \\
\text { Load }\end{array}$} & \multicolumn{4}{|c|}{ Airflow velocity } \\
\hline & $1 \mathrm{~m} / \mathrm{s}$ & $2 \mathrm{~m} / \mathrm{s}$ & $3 \mathrm{~m} / \mathrm{s}$ & $4 \mathrm{~m} / \mathrm{s}$ \\
\hline $20 \mathrm{~W}$ & 115.4 & 114.8 & 109.5 & 100.1 \\
\hline $40 \mathrm{~W}$ & 174.2 & 178.6 & 172.3 & 163.5 \\
\hline $60 \mathrm{~W}$ & 229. & 32 & 4 & 219.8 \\
\hline $80 \mathrm{~W}$ & 285.1 & 297.8 & 285.4 & 271.6 \\
\hline
\end{tabular}

(b) Heat Source \#2

\begin{tabular}{|c|c|c|c|c|}
\hline \multirow{2}{*}{$\begin{array}{l}\text { Heat } \\
\text { Load }\end{array}$} & \multicolumn{4}{|c|}{ Airflow velocity } \\
\hline & $1 \mathrm{~m} / \mathrm{s}$ & $2 \mathrm{~m} / \mathrm{s}$ & $3 \mathrm{~m} / \mathrm{s}$ & $4 \mathrm{~m} / \mathrm{s}$ \\
\hline $20 \mathrm{~W}$ & 79.3 & 73.4 & 71.1 & 66.7 \\
\hline $40 \mathrm{~W}$ & 28.9 & 3.9 & 108.4 & 105.0 \\
\hline $60 \mathrm{~W}$ & 2.4 & 52.8 & .6 & 139.1 \\
\hline $80 \mathrm{~W}$ & 217.2 & 191.3 & 176.6 & 169.8 \\
\hline
\end{tabular}

(c) Heat Source \#3

\begin{tabular}{|c|c|c|c|c|}
\hline \multirow{2}{*}{$\begin{array}{l}\text { Heat } \\
\text { Load }\end{array}$} & \multicolumn{4}{|c|}{ Airflow velocity } \\
\hline & $1 \mathrm{~m} / \mathrm{s}$ & $2 \mathrm{~m} / \mathrm{s}$ & $3 \mathrm{~m} / \mathrm{s}$ & $4 \mathrm{~m} / \mathrm{s}$ \\
\hline $20 \mathrm{~W}$ & 70.9 & 67.7 & 63.8 & 64.5 \\
\hline $40 \mathrm{~W}$ & 121.7 & 106.9 & 98.6 & 97.7 \\
\hline $60 \mathrm{~W}$ & 166.7 & 148.4 & 136.7 & 131.3 \\
\hline $80 \mathrm{~W}$ & 209.2 & 185.0 & 167.8 & 161.9 \\
\hline
\end{tabular}

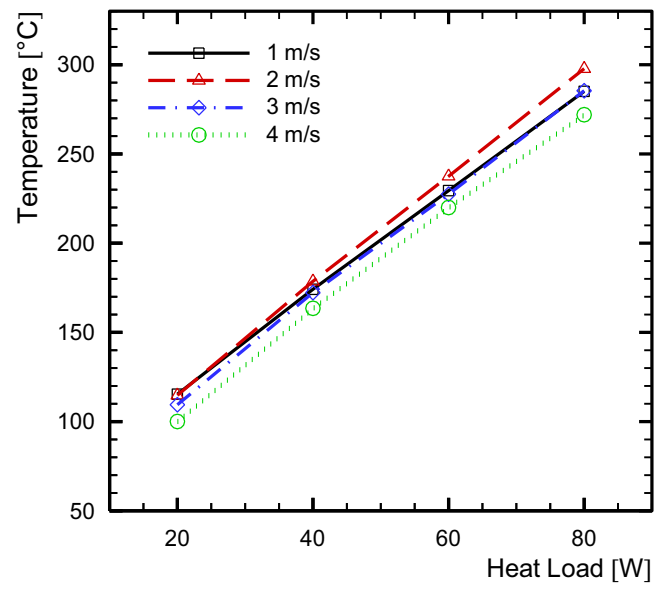

(a) Heat Source \#1

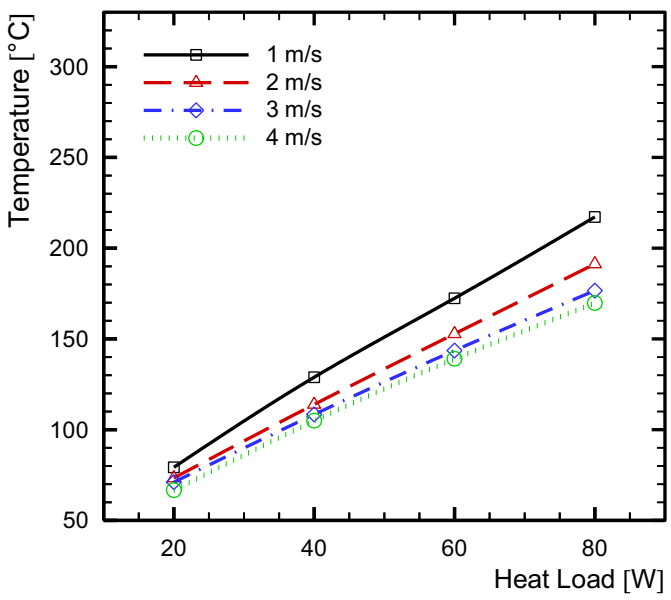

(b) Heat Source \#2

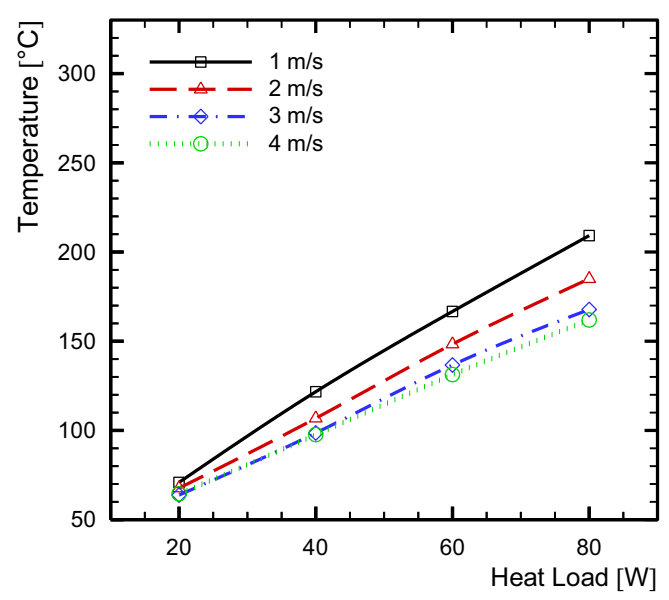

(c) Heat Source \#3

Figure 6. Average temperature versus heat load parameterized in the velocity to different heat source positions.

\section{Conclusions}

The results showed that a properly designed and manufactured $\mathrm{Cu}-\mathrm{Mo}$ alloy vapor chamber with capillary structures composed by $\mathrm{Cu}$ screen meshes maintain low operating temperature as a $\mathrm{Cu}$ vapor chamber with sintered $\mathrm{Cu}$ powder capillary structure. However, manufacturing vapor chambers with overlapped screen meshes in capillary structures are easier and cheaper. 


\section{References}

1. A. Shakouri, Y. Zhang, K. Fukutani, Solid-state microrefrigerator on a chip, Electronics Cooling 12, 18-26 (2006).

2. K. Azar, N. Engelberts, C. Goodman, M. Haskell, M. Pourvash, B. Tavasolli, Spreading thermal resistance: its definition and control, Thermal eMagazine I, 9599 (2008).

3. D.A. Reay, P.A. Kew, R.J. McGlen, Heat Pipe: Theory, Design and Applications, ButterworthHeinemann (2013).

4. Y. Koito, H. Imura, M. Mochizuki, S. Torii, Numerical analysis and experimental verification on thermal fluid phenomena in a vapor chamber, Applied Thermal Engineering 26, 1669-1676 (2006).

5. Y.S. Chen, K.H. Chein, T.C. Hung, C.C. Wang, Y.M. Feng, B.S. Pei, Numerical simulation of a heat sink embedded with a vapor chamber and calculation of effective thermal conductivity of a vapor chamber, Applied Thermal Engineering 29, 2655-2664 (2009)

6. D.H.S. Obata, T. Antonini Alves, M.A. Bazani, A.T Paschoalini, Experimental analysis of a vapor chamber applied to thermal management of microelectronics, Advanced Materials Research 1120, 1368-1372 (2015) 